Article

\title{
Lidar Prediction of Small Mammal Diversity in Wisconsin, USA
}

\author{
Sarah L. Schooler ${ }^{1, * \mathbb{C}}$ and Harold S. J. Zald ${ }^{2}$ \\ 1 Wildlife Department, Humboldt State University, 1 Harpst Street, Arcata, CA 95521, USA \\ 2 Forestry Department, Humboldt State University, 1 Harpst Street, Arcata, CA 95521, USA; \\ hsz16@humboldt.edu \\ * Correspondence: sarahlschooler@gmail.com or ss665@humboldt.edu; Tel.: +1-608-698-4770
}

Received: 31 July 2019; Accepted: 22 September 2019; Published: 24 September 2019

\begin{abstract}
Vegetation structure is a crucial component of habitat selection for many taxa, and airborne LiDAR (Light Detection and Ranging) technology is increasingly used to measure forest structure. Many studies have examined the relationship between LiDAR-derived structural characteristics and wildlife, but few have examined those characteristics in relation to small mammals, specifically, small mammal diversity. The aim of this study was to determine if LiDAR could predict small mammal diversity in a temperate-mixed forest community in Northern Wisconsin, USA, and which LiDAR-derived structural variables best predict small mammal diversity. We calculated grid metrics from LiDAR point cloud data for 17 plots in three differently managed sites and related the metrics to small mammal diversity calculated from five months of small mammal trapping data. We created linear models, then used model selection and multi-model inference as well as model fit metrics to determine if LiDAR-derived structural variables could predict small mammal diversity. We found that small mammal diversity could be predicted by LiDAR-derived variables including structural diversity, cover, and canopy complexity as well as site (as a proxy for management). Structural diversity and canopy complexity were positively related with small mammal diversity, while cover was negatively related to small mammal diversity. Although this study was conducted in a single habitat type during a single season, it demonstrates that LiDAR can be used to predict small mammal diversity in this location and possibly can be expanded to predict small mammal diversity across larger spatial scales.
\end{abstract}

Keywords: small mammals; Lidar; remote sensing; diversity; Wisconsin; vegetation structure; habitat; forest

\section{Introduction}

A fundamental part of habitat is three-dimensional (3D) heterogeneity, which has been established as a key determinant of animal diversity, especially in forests [1,2]. This has been studied extensively using field-based survey methods to measure forest structure, in conjunction with wildlife surveys [1,2]. However, using field-based methods to measure structural diversity in forests is difficult, expensive and time-intensive. Thus, using field-based methods to measure the relationship between structural habitat characteristics and animal diversity at larger spatial scales is not feasible. Remote sensing, specifically airborne LiDAR (Light Detection and Ranging) provides an alternative to ground based surveys and is a relatively inexpensive way to obtain detailed and spatially complete characterizations of horizontal and vertical vegetation structure across large areas [3]. LiDAR is increasingly used to study and predict habitat suitability for a variety of species across a range of taxa [4].

Though multiple species-habitat relationships have been studied using LiDAR, the majority have examined the abundance and diversity of animals dependent on three-dimensional ecology, specifically avian species $[4,5]$. A limited number of studies have been conducted on abundance of other 3D 
dependent animals such as fox squirrels, monkeys, and bats and fewer still on other land-dwelling terrestrial mammals [4]. While 3D ecology is crucial to birds and other arboreal species, vertical structural habitat factors also significantly impact small mammals (here defined as mammals that are nonvolant, nocturnally active, forage above-ground, and weigh less than 600 grams) $[6,7]$.

Structural habitat variables such as coarse woody debris; understory vegetation; and the age, structure, or heterogeneity of forest stands can influence the diversity and abundance of small mammal species by affecting food availability, nesting sites, and shelter from predators $[6,8,9]$. Though some small mammal species are primarily impacted by understory characteristics, even ground-dwelling small mammals can be impacted by vertical structural characteristics $[6,8,10]$. These characteristics, especially the structure and heterogeneity of forest stands, can be extrapolated from LiDAR data, which establishes a link between small mammal habitat quality and LiDAR-derived habitat variables [3].

The few prior studies on remotely-sensed habitat suitability for small mammals have found LiDAR effectively predicts small mammal habitat use. However, these studies are focused on abundance and habitat use of single species, rather than overall small mammal community diversity [11-13]. Small mammals crucially contribute to ecosystem function through their roles in seed propagation, organic matter decomposition, and soil mixing [14-16]. Additionally, they are an important food source for many predators [17]. Given that, because different species have different roles in ecosystems, animal species diversity positively contributes to ecosystem services [18], it is important to measure small mammal diversity, since it likely contributes to ecosystem health $[2,19]$.

Given the ecological importance of small mammal diversity, a low-cost alternative to field surveys, such as LiDAR, would be beneficial to measure small mammal diversity on a larger scale [20]. If small mammal diversity is related to LiDAR-derived habitat variables, then LiDAR can be more broadly applied for inventory and monitoring of small mammal communities at large spatial scales. In this study, first we examine if vegetation structure derived from LiDAR can predict small mammal diversity in a temperate-mixed community in the Great Lakes region, and second, we determine which LiDAR-derived vegetation structure variables best predict small mammal diversity.

\section{Materials and Methods}

\subsection{Study Area}

This study used data from three sites in the Great Lakes Region (Domain 5) from the Battelle Ecology Incorporated National Ecological Observatory Network (NEON): Chequamegon-Nicolet National Forest site (CNNF), Treehaven site (TREE), and University of Notre Dame Environmental Research Center site (UNDE) (Figure 1). These three study sites are in northern Wisconsin, have different management strategies, and are no farther than $100 \mathrm{~km}$ apart (Figure 1). Site elevations range from 450 and $500 \mathrm{~m}$ above sea level. The climate in northern Wisconsin is classified as a warm summer continental climate with average summer high temperatures of $18^{\circ} \mathrm{C}$ and average winter low temperatures of $-14{ }^{\circ} \mathrm{C}$. Average precipitation in northern Wisconsin is $850 \mathrm{~mm}$ evenly distributed throughout the year. All forests for these sites are primarily comprised of natural or replanted second-growth forests due to extensive logging in the late 1800s and early 1900s and subsequent use of the land for cattle grazing and farming [21].

In this region, upland ecosystems include: northern mesic deciduous forests (National Land Cover Database (NLCD) classification deciduous forest) with dominant tree species consisting of maple (Acer rubrum and A. saccharum), aspen (Populus tremuloides and P. gradidentata), and paper birch (Betula papyifera) and mixed evergreen forests (NLCD classification mixed forest) with dominant species balsam fir (Abies balsamea), hemlock (Tsuga canadensis), pine (Pinus resinosa and P. strobus), and white spruce (Picea glauca). Lowland ecosystems (NLCD classification woody wetlands) include: open sedge and shrub wetlands; wet evergreen forests or sphagnum bogs consisting primarily of cedar (Thuja occidentalis), black spruce (Picea mariana), and tamarack (Larix larcina)); and deciduous forest wetlands with dominant species alder (Alnus incana) [22]. 
The most common small mammals in the region include thirteen-lined ground squirrel (Ictidomys tridecemlineatus), eastern chipmunk (Tamias striatus), voles (Microtus pennsylvanicus and Myotes gapperi), stoat (Mustela ermine), shrews (Sorex articus, S. cinereus, S. hoyi, and Blarina bevicauda), Kansas bog lemming (Synaptomys cooperi), and mice (Zapus hudsonius and Peromyscus maniculatus gracilis) [10].

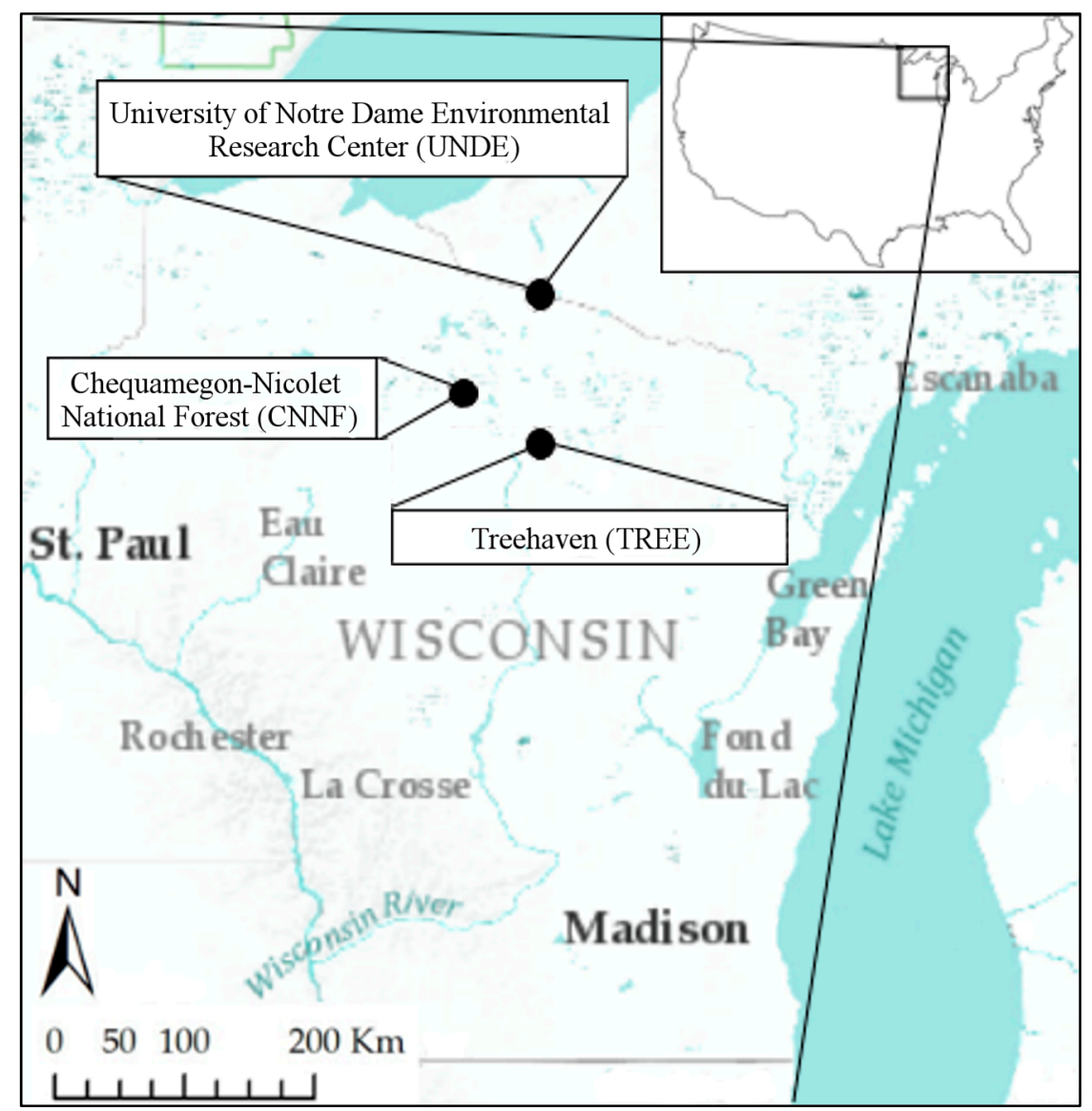

Figure 1. Map of Great Lakes Domain National Ecological Observatory Network (NEON) study sites in Wisconsin, USA.

The CNNF study site $\left(45.80^{\circ} \mathrm{N}, 90.06^{\circ} \mathrm{W}\right)$ is a $22 \mathrm{~km}^{2}$ site located within Chequamegon-Nicolet National Forest (Figure 1). The national forest was planted in the 1930s and is currently managed with an uneven aged management strategy using 10 to 20 year intervals, with thinning and canopy gaps used as necessary [23]. Six small mammal plots were sampled at the CNNF site in 2016 (Figure 1, Table S1) [24]. The TREE study site $\left(45.48^{\circ} \mathrm{N}, 89.56^{\circ} \mathrm{W}\right)$ includes all of Treehaven experimental forest and spans $5 \mathrm{~km}^{2}$ (Figure 1). The forest is primarily a second-growth forest planted in the 1950s [21]. Treehaven is an experimental and recreational forest and as such is managed using a variety of strategies such as conventional and long-rotation harvests, partial harvests, prescribed burning, and experimental controls [21]. Six small mammal plots were sampled at the TREE site in 2016, but two were excluded from this analysis: one due to recent logging, and another due to insufficient trapping effort (Figure 1, Table S1) [24]. The UNDE study site $\left(46.24^{\circ} \mathrm{N}, 89.52^{\circ} \mathrm{W}\right)$ includes all of the University of Notre Dame Environmental Research Center, which measures $30 \mathrm{~km}^{2}$ (Figure 1). This forest is comprised of primarily second-growth stands planted in the 1930s. The forest was harvested selectively until approximately 1970. Since 1970, the forest has been minimally managed and is maintained as an environmental education and research facility. Seven small mammal plots were sampled at the UNDE site in 2016 (Figure 1, Table S1) [24]. Overall, 17 small mammal plots were used for data analysis: 6 from CNNF, 4 from TREE, and 7 from UNDE (Figure 1, Table S1). 


\subsection{Data Source and Collection}

Discrete return airborne LiDAR flown by NEON in 2016 was used to calculate measures of structural complexity for each small mammal plot [25]. LiDAR data was collected during peak phenology (9 September-15 September 2016) and flown on average $1000 \mathrm{~m}$ above ground level [26]. Data was collected from a fixed-wing aircraft with an Optech ALTM Gemini system with a pulse repetition frequency of $100 \mathrm{kHz}$, beam footprint of $0.8 \mathrm{~m}$, scan swath overlap of approximately $50 \%$, and scan angle of $\pm 18^{\circ}$ [26-28]. There was a maximum of 4 returns per pulse and all locations had greater than 2.5 returns per square meter with an average of 5.5 returns per square meter. We also used one meter resolution high-quality digital elevation models (DEMs) generated by NEON from LiDAR data using a triangular irregular network algorithm [26,29].

Small mammal trapping was conducted by NEON in accordance with the NEON TOS Small Mammal Trapping Protocol [7]. NEON small mammal plots were generated and delineated through spatially balanced random selection [30]. NEON did not collect structural habitat information within small mammal plots to avoid disturbance of plots that may have interfered with small mammal capture [7]. Each small mammal plot was a ten column by ten row trap grid with an inter-trap distance of $10 \mathrm{~m}$, for a total of 100 traps per plot (Figure 2) [7]. The four corners of each grid and the center of each grid were established with high accuracy GPS $(\leq 30 \mathrm{~cm})$ [30]. To include adequate area surrounding each trap, for purposes of this analysis, each plot was buffered on all sides by $5 \mathrm{~m}$, creating 10,000 $\mathrm{m}^{2}$ plots (Figure 2). Due to the variable sizes of small mammal home ranges and to better incorporate smaller-scale structural habitat features we decided to conduct an analysis on two scales: a plot-level analysis and a subplot level analysis [25,31]. For the subplot level analysis, each plot was divided into 4 squares of $2500 \mathrm{~m}^{2}$ with 25 traps in each (Figure 2). We excluded smaller area analysis, such as trap-level analysis, due to low average trap success (mean number of captures per trap $=0.39$, standard deviation $=0.63 ; 67 \%$ of traps had no captures over the time period sampled).

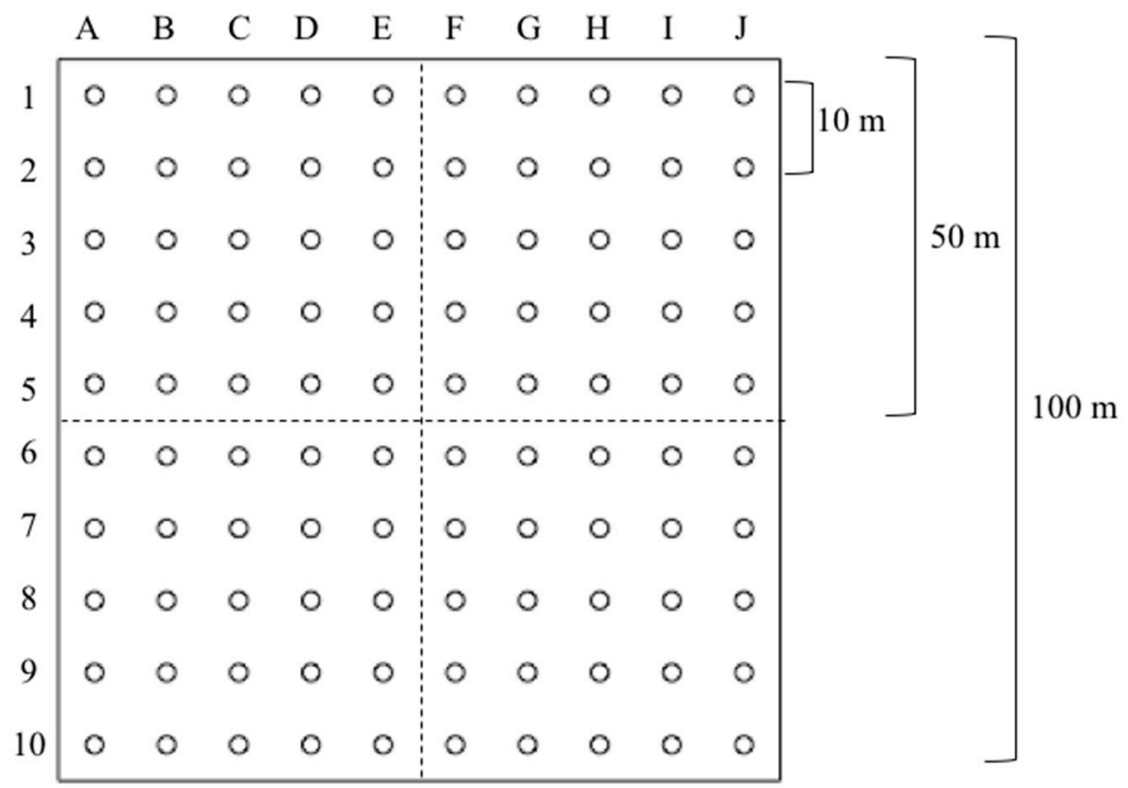

Figure 2. Layout of small mammal plots and subplots in northern Wisconsin, USA, with identification letters and numbering scheme as well as measurements. Traps are identified as circles (10 $\mathrm{m}$ apart) and subplots $\left(\mathrm{n}=4,50 \mathrm{~m}^{2}\right)$ are identified as black dashed lines within the larger black square plot $\left(100 \mathrm{~m}^{2}\right)$. The trap grids are identified horizontally alphabetically and vertically numerically.

Small mammal trapping was conducted once per month within ten days of the new moon totaling five times between late May and late August 2016 [21]. Sherman traps were baited with 1/8 cup of bird seed and filled with a small handful of polyester fluff for small mammal temperature regulation [7]. 
Traps were set within two hours of sunset and checked within two hours of sunrise. Trapped animals were processed and then released. Small mammal recaptures within 2016 were determined based on ear-tag numbers and removed from the dataset. We used data from 2016 only given the limited lifespans of small mammals and the possibility of forest changes throughout the year [10,32].

\subsection{Data Preparation}

All LiDAR processing was conducted using R version 3.5.1 using packages lidR and raster [33-35]. The LiDAR data and DEM for each plot and subplot were clipped, and a normalized return point cloud (height as elevation above ground) was generated for each plot and subplot $\left(10,000,2500 \mathrm{~m}^{2}\right.$ respectively) [36]. Using the clipped point cloud, we created a canopy height model from first returns using nearest neighbor interpolation [37]. We calculated gridded metrics from the LiDAR point cloud with the objective of categorizing horizontal structure and vertical structure across different vegetation strata (Table 1) $[5,11]$. To avoid spurious relationships, autocorrelation, and model overfitting, we used five variables that included a range of forest structure indices that may impact small mammal ecology: canopy height, percent cover above two meters ("cover"), proportion contribution of vegetation below five meters in height (approximating vegetation below the forest canopy, including trunks of trees and snags) ("understory contribution"), canopy complexity as measured by coefficient of variation of height of points above five meters ("canopy complexity"), and vertical complexity as measured by Shannon entropy ("structural diversity") (Table 1, Figure S1). Shannon diversity index for vertical complexity is the Shannon Weaver index for species diversity applied to quantify the diversity and evenness of a stand structure as calculated by Equation (1) [38]:

$$
H^{\prime}=\frac{\sum_{i}^{S} p_{i} \ln \left(p_{i}\right)}{\log (S)}
$$

where $H^{\prime}$ is the normalized Shannon diversity index for vertical complexity where $p_{i}$ is the proportion of points in the $i$ th one-meter bin, and $S$ is the number of bins equal to the total height in meters rounded up to the nearest integer. In this case, the index uses equal one meter height bins in the vertical distribution of LiDAR points to quantify structural diversity and evenness of the point cloud in each one meter cell [33]. The term "understory" used in this study is significantly different than the technical term of "understory", and no inference should be expanded to the formal "forest understory".

Given incomplete knowledge about how vertical structure influences habitat for small mammals in northern Wisconsin, we used LiDAR-derived metrics that best encompassed different vegetation structure attributes without using correlated or redundant variables. These metrics were based on similar research on LiDAR related to animal habitat, expert knowledge of the ecosystem, and previous studies on LiDAR descriptors of forest structure $[5,6,10,11,39,40]$. We created gridded metrics at the 1 $\mathrm{m}$ scale, then averaged all cells for each raster of plot and subplot. Site was included as a categorical predictor to account for geographic location and management style differences between sites.

For each plot and subplot, we summed small mammal species caught across all four months, removed re-captures, and then calculated small mammal richness and the effective Shannon species diversity index ("small mammal diversity"), which takes into account species richness while weighting species according to relative frequency in the population [41-43]. The Shannon diversity index for species diversity is calculated through Equation (1), where $p_{i}$ is the proportion of species made up of the $i$ th species, and $S$ is the total number of species in the community (richness). We exponentiated the raw small mammal Shannon diversity values with a base of $e$ to convert them to their numerical equivalents to avoid problems that can arise from using raw indices [41,43].

\subsection{Modeling}

To test which LiDAR-derived variables best predicted small mammal diversity and richness, we developed linear regressions of LiDAR-derived predictor variables with small mammal diversity and 
richness as the dependent variables on both plot and subplot levels. A candidate model set was developed for both response variables (small mammal diversity and small mammal richness) with all first order combinations of LiDAR variables and site as predictors (Table 1) [44]. Additionally, we created null models for small mammal diversity and richness with NEON-provided national land cover database (NLCD) categorization as the predictor variable (Table S1) [30]. NEON NLCD categorization is based on Anderson's land use and land cover classification system updated by the Multi-Resolution Land Characteristics Consortium, which is then verified in the field by NEON technicians $[30,45,46]$. Non-categorical predictors were tested for correlation; no variables were correlated above 0.8 (Table S2). We used the R package glmulti to test all linear models in our cantidate model sets, then calculated log-likelihood and Akaike's Information Criteria adjusted for small sample size for each model (AICc) [44]. The top model selected by AICc was evaluated for goodness-of-fit using residual deviance, coefficient of determination $\left(\mathrm{R}^{2}\right)$, and root mean squared error (RMSE) from a six-fold cross validation [47]. Additionally, we normalized RMSE (RMSE divided by the range of observed values) in order to account for differences in variable scale. Because there were multiple models with similar AICc scores, $(\Delta \mathrm{AICC}<5)$, we used multimodel inference to determine which predictors had the highest sum of AIC weights across all models tested (importance) and the directionality of predictors [48].

Table 1. Summary of calculated predictor at plot scale $\left(100 \mathrm{~m}^{2}\right)$ across all plots at all sites. Predictor, method of calculation (Metric Calculation), dimension measured (Dimension), mean, standard deviation (St. Dev.), and range are presented for each variable. Height is expressed in meters, while remaining metrics are expressed in proportions.

\begin{tabular}{|c|c|c|c|c|c|}
\hline Predictor & Metric Calculation & Dimension & Mean & St. Dev. & Range \\
\hline Canopy Height (m) & Mean of the canopy height model & Average & 13.62 & 5.23 & $4.81-21.86$ \\
\hline Cover & $\begin{array}{l}\text { Number of first returns above } 2 \\
\text { m/total number of first returns }\end{array}$ & Vertical & 0.87 & 0.11 & $0.62-0.99$ \\
\hline $\begin{array}{l}\text { Understory } \\
\text { Contribution }\end{array}$ & $\begin{array}{l}\text { Number of returns above } 0.2 \mathrm{~m} \\
\text { and less than } 5 \mathrm{~m} / \text { total number } \\
\text { of returns }\end{array}$ & Horizontal & 0.34 & 0.21 & $0.05-0.70$ \\
\hline $\begin{array}{l}\text { Canopy } \\
\text { Complexity }\end{array}$ & $\begin{array}{l}\text { Coefficient of variation of height } \\
\text { for first returns above } 5 \mathrm{~m}\end{array}$ & Vertical & 0.89 & 0.09 & $0.65-0.98$ \\
\hline $\begin{array}{l}\text { Structural } \\
\text { Diversity }\end{array}$ & $\begin{array}{l}\text { Shannon structural entropy index } \\
\text { in } 1 \mathrm{~m} \text { bins }\end{array}$ & Vertical & 0.84 & 0.07 & $0.72-0.95$ \\
\hline
\end{tabular}

\section{Results}

A total of 14 different small mammal species were captured: Northern short-tailed shrew (Blarina brevicauda), flying squirrel (Glaucomys sp.), meadow vole (Microtus pennsylvanicus), southern red-backed vole (Myodes gapperi), woodland jumping mouse (Napaeozapus insignis), white-footed deermouse (Peromyscus leucopus), North American deermouse (Peromyscus maniculatus), arctic shrew (Sorex arcticus), cinereus shrew (Sorex cinereus), American pygmy shrew (Sorex hoyi), least chipmunk (Tamias minimus), Eastern chipmunk (Tamias striatus), red squirrel (Tamiasciurus hudsonicus), and meadow jumping mouse (Zapus hudsonius). Small mammal diversity varied drastically between plots but was similar between sites (ANOVA, $\mathrm{p}=0.75, \mathrm{f}=0.29$ ) (Tables S3 and S4, Figure 3). At the plot level, maximum calculated small mammal diversity was 7.89 , minimum calculated small mammal diversity was 1.79 , and mean small mammal diversity was 5.06 (standard deviation $=1.83$ ). Plot level maximum small mammal richness was 9, minimum small mammal richness was 2 , and mean small mammal richness was 6.76 (standard deviation $=2.19$ ). As small mammal diversity and richness were highly correlated (Pearson correlation $=0.92$ ) and model selection results were broadly similar, we only used small mammal diversity as our response variable in the models we present. Information on models fitted for small mammal richness are presented in supplementary information (Tables S5 and S6). 


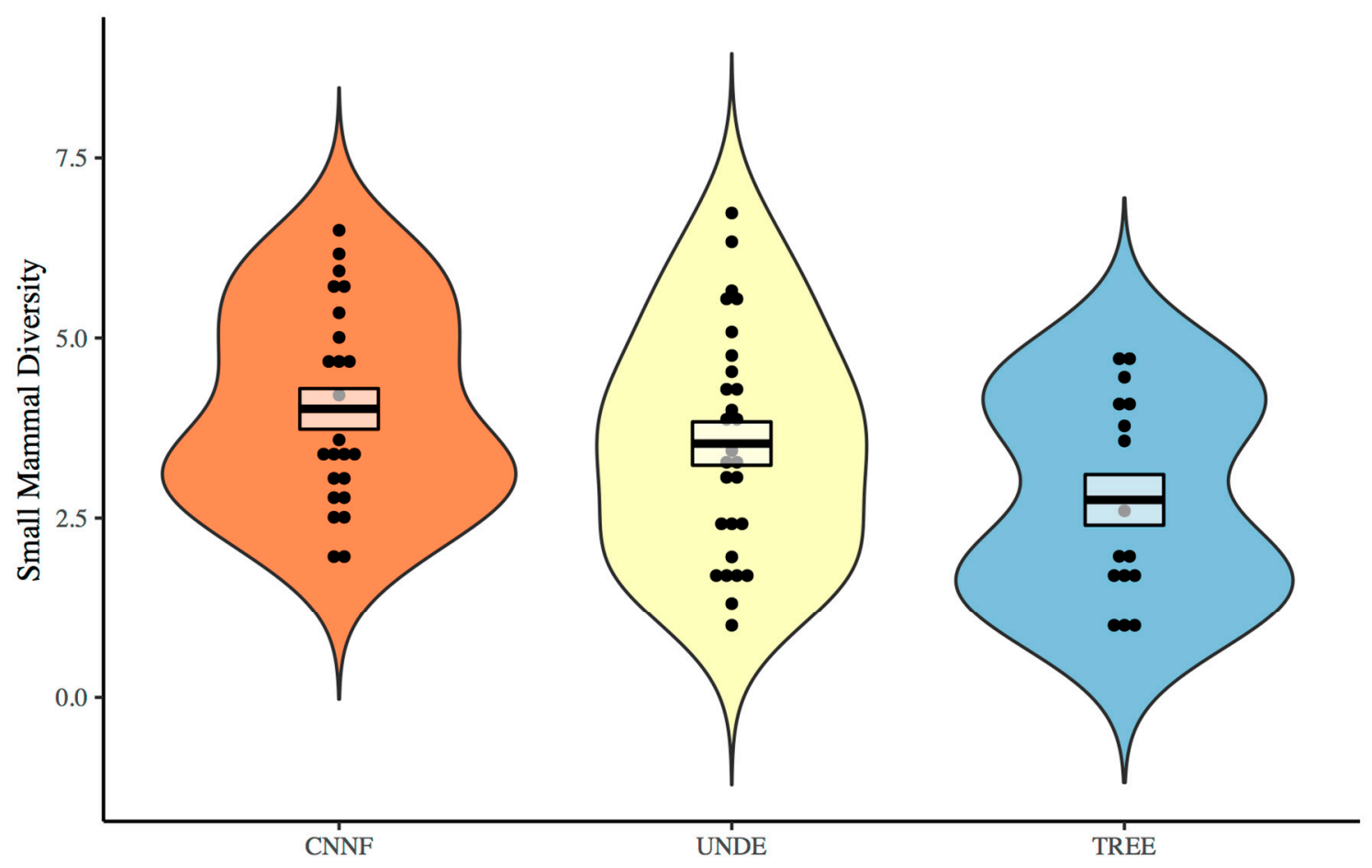

Figure 3. Violin plot of subplot small mammal diversity for sites CNNF, UNDE, and TREE; mean small mammal diversity (black horizontal bars) with $95 \%$ confidence intervals (white boxes) and range of small mammal diversity at each of the subplots (black dots) are presented.

All LiDAR-derived metrics were similar between sites (Table S4, MANOVA Wilks statistic $=0.48$, $\mathrm{F}=0.86, \mathrm{df}=10, \mathrm{p}=0.58$ ) but were variable between plots (Table 1 and Table S3, Figures 4 and 5). Average cover above two meters was high (0.87), and even the most open plot had relatively high cover (TREE 27, 0.62) (Table 1 and Table S3). Similarly, canopy complexity was also relatively high for all plots (mean $=0.89)$, as was structural diversity $($ mean $=0.84)$ (Table 1, Figures 4 and 5). Understory contribution on average was low (mean $=0.34)$, though it had a wide range (range $=0.05-0.70)$ (Table 1 and Table S3). Canopy height was also widely variable, ranging from an average plot canopy height of $4.81 \mathrm{~m}$ (UNDE 2) to $21.86 \mathrm{~m}$ (CNNF 12) (Table 1 and Table S3).

The best model to predict small mammal diversity on the plot scale included structural diversity and cover (Table 2, Equation S1; residual deviance $=25.20, \mathrm{R}^{2}=0.53, \mathrm{RMSE}=0.67$, normalized RMSE $=0.108$ ). The best model to predict small mammal diversity on a subplot scale included structural diversity, cover, canopy complexity, and site (Table 3, Equation S2; residual deviance $=89.20, \mathrm{R}^{2}=0.43$, RMSE $=0.51$, normalized RMSE $=0.089$ ). Though small mammal diversity did not significantly differ between sites, site was included in the best model for small mammal diversity at a subplot scale (Table 4, Figure 3). Top models were significantly better performing than our null model using only NLCD (Plot-level AICc $=73.34, \triangle \mathrm{AICc}=7.08$, residual deviance $=38.20, \mathrm{R}^{2}=0.29$, subplot-level AICc $=250.66, \Delta \mathrm{AICC}=23.36$, residual deviance $\left.=139.89, \mathrm{R}^{2}=0.11\right)$.

There was a high degree of uncertainty in model selection, since on both plot-level and subplot level scales there were at least five models within four AICc of the top model. Model averaging revealed that structural diversity was the most important predictor on plot and subplot scales (Table 4, Figure 5). Structural diversity had a positive relationship with small mammal diversity on both scales, while canopy height and cover had negative relationships with small mammal diversity (Table 4, Figure 5). 
Table 2. Top five models as ranked by AICc for small mammal diversity for plot-level analysis with degrees of freedom (df), log-likelihood values (LogLik), AICc values (AICc), delta AICc values ( $\triangle$ AICc), and weight $(\mathrm{w})$.

\begin{tabular}{cccccc}
\hline Model Name & df & logLik & AICc & $\Delta$ AICc & w \\
\hline Structural Diversity + Cover & 4 & -27.46 & 66.26 & 0.00 & 0.19 \\
Structural Diversity + Canopy Height & 4 & -27.62 & 66.58 & 0.32 & 0.16 \\
Structural Diversity & 3 & -29.51 & 66.86 & 0.60 & 0.14 \\
Structural Diversity + Understory Contribution & 4 & -28.09 & 67.51 & 1.25 & 0.10 \\
Cover + Canopy Complexity & 4 & -28.58 & 68.49 & 2.23 & 0.06 \\
\hline
\end{tabular}

Table 3. Top five models as ranked by AICc for small mammal diversity for subplot-level analysis with degrees of freedom (df), log-likelihood values (LogLik), AICc values (AICc), delta AICc values $(\triangle \mathrm{AICc})$, and weight $(\mathrm{w})$.

\begin{tabular}{cccccc}
\hline Model Name & df & logLik & AICc & $\Delta$ AICc & w \\
\hline Structural Diversity + Cover + Canopy & 7 & -105.72 & 227.30 & 0.00 & 0.17 \\
Complexity + Site & 6 & -107.83 & 229.04 & 1.75 & 0.07 \\
Structural Diversity + Cover + Site & 5 & -109.07 & 229.10 & 1.81 & 0.07 \\
Structural Diversity + Cover & 3 & -111.41 & 229.19 & 1.90 & 0.06 \\
$\quad$ Structural Diversity & 5 & -109.16 & 229.28 & 1.98 & 0.06 \\
Structural Diversity + Site & & &
\end{tabular}

Table 4. Table of parameter contributions to models ranked by weighted importance of the parameter, with the standardized average parameter estimate across all models to which the parameter contributed (Estimate), the standardized variance of the estimated parameter (Variance), and the weighted importance of the parameter (Importance) for both scales [34]. Estimates and variances were standardized around the standard deviation of the variable. The site variable, because it was categorical, was treated as an indicator variable, and thus the parameter estimates for TREE and UNDE are relative to CNNF estimates.

\begin{tabular}{cccc}
\hline Parameter & Estimate & Variance & Importance \\
\hline & Plot & & \\
\hline Structural Diversity & 0.532 & 0.324 & 0.83 \\
Canopy Height & -0.177 & 0.323 & 0.37 \\
Cover & -0.112 & 0.228 & 0.33 \\
Understory Contribution & 0.084 & 0.207 & 0.25 \\
Canopy Complexity & 0.080 & 0.252 & 0.23 \\
Site (TREE, UNDE) & $0.001,0.001$ & $0.031,0.034$ & 0.02 \\
\hline & Subplot & & \\
\hline Structural Diversity & 0.573 & 0.119 & 1.00 \\
Cover & -0.186 & 0.209 & 0.61 \\
Site (TREE, UNDE) & $-0.159,-0.07$ & $0.159,0.105$ & 0.60 \\
Canopy Complexity & 0.144 & 0.186 & 0.54 \\
Canopy Height & -0.034 & 0.124 & 0.30 \\
Understory Contribution & 0.002 & 0.075 & 0.25 \\
\hline
\end{tabular}




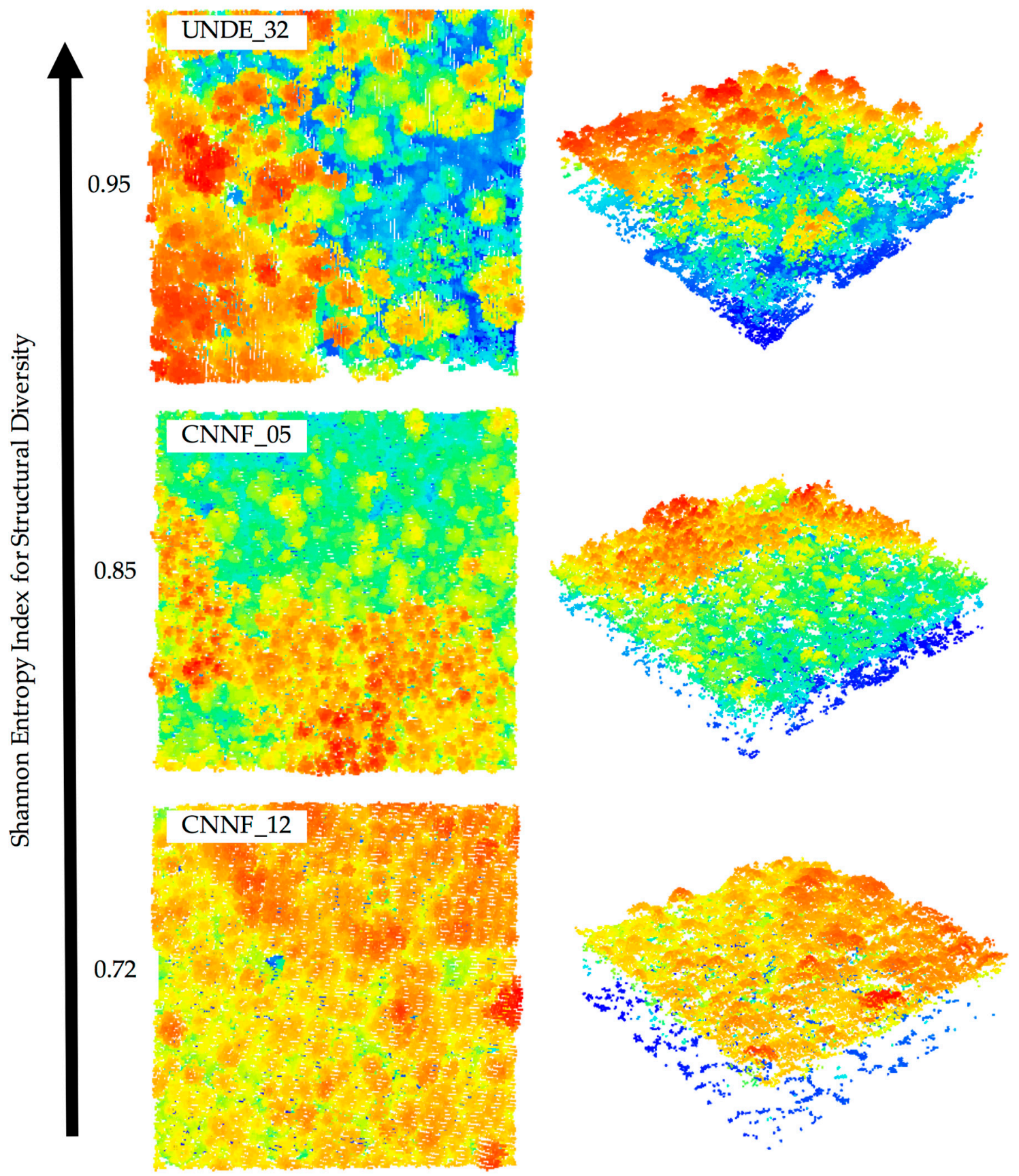

Figure 4. Examples of LiDAR point clouds for three plots analyzed with corresponding Shannon Entropy indices for forest structural diversity. Each of three-point clouds is labeled with the site and plot number and presented in both aerial view and slanted view. Sites are arranged in increasing order for calculated structural diversity. Color scale is standardized with the same maximum and minimum for all three plots. 


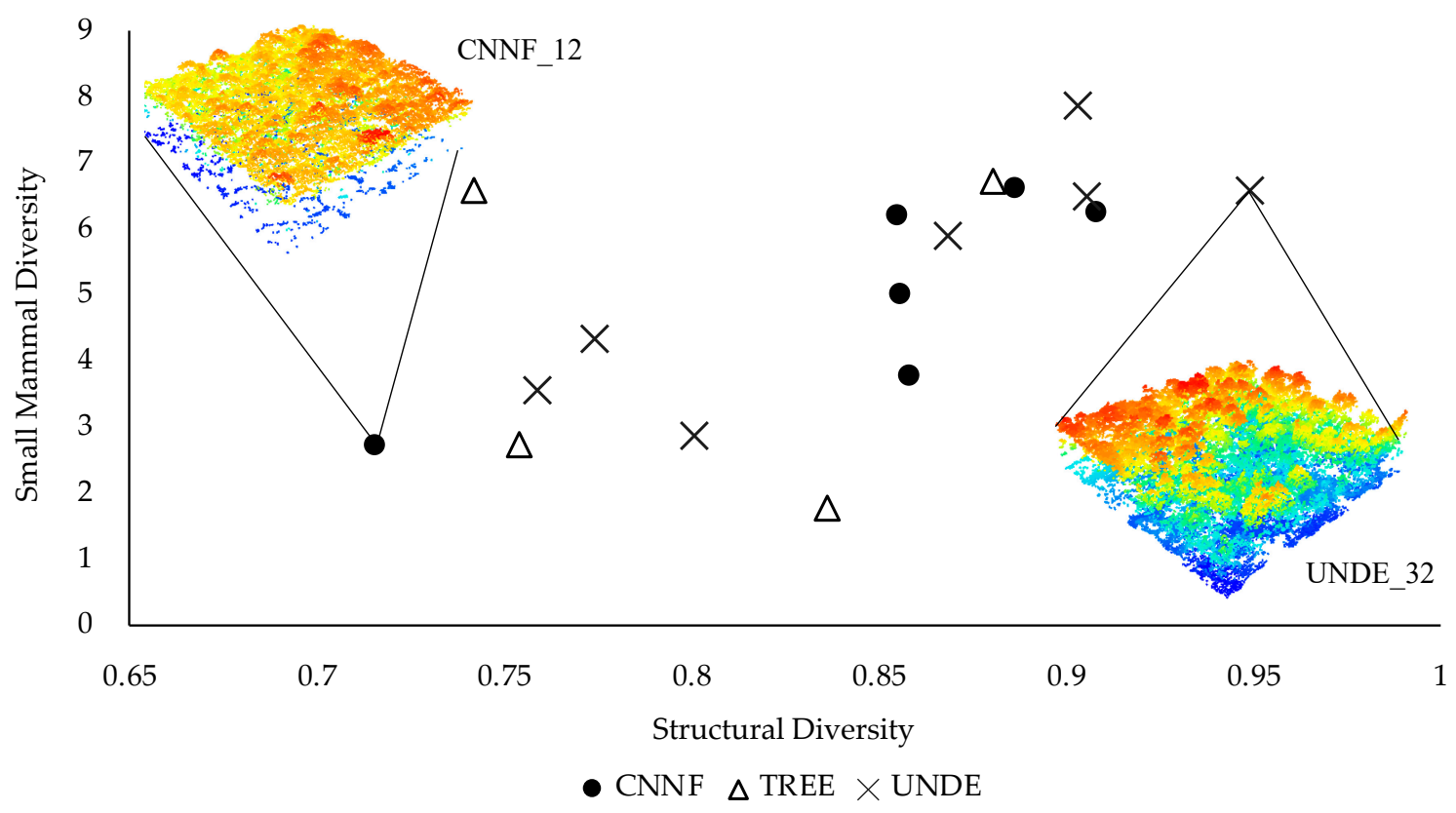

Figure 5. Relationship between plot-level small mammal diversity and structural diversity, classified by site, with example LiDAR point clouds for the lowest and highest structurally diverse plots.

\section{Discussion}

We found that small mammal diversity was associated with LiDAR-derived structural vegetation metrics. Our results show that LiDAR-derived variables predict the relationship between forest structure and small mammal diversity similarly to the way forest structure variables derived from field-based measurements relate to small mammal diversity [8,49]. Our best models using LiDAR variables to predict small mammal diversity fit well, indicating that LiDAR variables were able to predict variation in small mammal diversity. This is consistent with prior research that has shown that LiDAR can predict 3D-dependent animal species diversity [5,49-51]. In addition, it is consistent with the few studies that have demonstrated the ability of LiDAR variables to predict single-species habitat suitability, and abundance for small mammals $[11,13,52]$. On both scales analyzed, structural diversity and canopy cover were the best predictors of small mammal diversity, while site was important on only a subplot scale. Below, we discuss our results in detail in the context of different spatial scales of habitat characterization, along with the potential limitations of LiDAR for monitoring small mammal diversity.

Structural diversity was positively related to small mammal diversity at both plot and subplot scales. This finding agrees with the habitat heterogeneity hypothesis, which predicts that increased structural complexity can provide more niches and increase species diversity and richness. This hypothesis has been established across a broad range of taxa, including small mammals [1,2]. Our results agree with previous studies where field measurements have shown forest structural diversity to be positively correlated with small mammal species diversity $[2,8]$. Spatial heterogeneity in forest canopies leads to increased diversity of small mammals due to increased diversity of vegetation that contributes to biocomplexity and niche diversification $[10,53,54]$. However, some of this diversity is driven by variation in tree-dependent small mammals such as squirrels and chipmunks, while diversity of ground-dwelling small mammals is less impacted by vertical heterogeneity $[10,53]$.

Small mammal diversity decreased with increasing canopy cover. Several studies have shown that forest-floor small mammal diversity increases with forest thinning, and forest management has been shown to impact small mammal diversity $[53,55,56]$. Higher small mammal diversity in plots and subplots of lower average cover may be due to canopy gaps potentially created through selective logging [11,53]. Even if site management does not generate gaps, natural gaps in the forest likely contribute to structural habitat heterogeneity. Gaps promote growth of understory vegetation, which 
provides food and shelter for small mammal species [11,57]. Future analysis should include gap quantification using LiDAR to test whether number and size of gaps are significant predictors for small mammal diversity.

At the subplot scale, site as a proxy for management style was an important predictor of small mammal diversity. Thus, current site management may influence small mammal diversity, but the effect was possibly not evident at a plot scale due to small sample size. Spatial heterogeneity caused by forest management is known to positively impact small mammal diversity [32,53]. One of the managed sites (CNNF) had the highest small mammal diversity, which is consistent with prior research. However, the site with the second highest small mammal diversity had minimal management (UNDE), while the site with the lowest small mammal diversity was also a managed forest (TREE). Due to the nature of forest management at TREE, because it is an experimental forest, there is likely a great deal of variation in stand age and management strategies. As UNDE was selectively logged until 1970, some or all of the plots that were sampled at UNDE may continue to have characteristics of managed forests. Lack of field data and detailed information on management activities at sites preclude any further quantification of management derived modification of forest structure and its possible effects on small mammal diversity.

The lack of selection of understory contribution as a significant variable may reflect the limitations of airborne LiDAR. In areas with high leaf area index, LiDAR with relatively low point density may not adequately penetrate the canopy, leading to poor quantification and characterization of understory structure [27,39]. LiDAR sensors with higher point densities better penetrate the canopy, which could improve characterization of lower vegetation strata [39]. Terrestrial LiDAR could also be used for improved data on understory, but like field data, terrestrial LiDAR has limitations with respect to cost and incomplete spatial coverage at a larger scale [58].

An additional caveat when considering understory contribution is that it was calculated as proportion returns below five meters. Though creating a height threshold to characterize the forest layers below the canopy is a commonly used technique in LiDAR analysis of forest structure [39,57], it can be problematic because the height threshold may be considered arbitrary. Snags, stumps, and tree trunks are also not separated from low vegetation or shrubs in this method $[59,60]$. Though we used a height threshold determined through review of previous research, knowledge of the ecosystem, and our canopy height model, a more precise analysis would include a model to delineate subcanopy layers and woody basal area using LiDAR from areas of known vegetation structure $[57,60,61]$. This approach is not possible with our data, given that no vegetation structure data is collected on NEON small mammal plots, but future research should better incorporate understory mapping, especially when examining trends of animals that live on the forest floor.

Although model-averaging revealed that the variances for some selected variables overlapped zero, there was concurrence between the variables selected in the top model and the variables with the highest importance factors. This leads us to conclude that the top variables are important in predicting small mammal diversity, however the directionality is less certain, and there may be variables that we did not include in our analysis that account for more variation.

Little is known about the specific impact of forest structure on small mammal diversity and less still on how LiDAR measurements of forest structure relate to the life history requirements of multiples species of small mammals [12,62]. Thus, we analyzed the ability of few specific variables that encompass a wide range of forest structural attributes to predict small mammal diversity. The lack of specific knowledge on the relationship between vertical structure and small mammal habitat requirements may cause a disconnect between the variables we have identified as potentially being important for small mammal habitat and what small mammal species actually require in their habitat, which may alter the perceived relationship between small mammal diversity and forest structure [63].

LiDAR variables also suffer from autocorrelation, given that all variables are calculated from the same base dataset. Though we ensured our variables were correlated less than 0.8 , correlation of variables may have skewed our results. Additionally, this study was conducted with a relatively 
small sample size, which may lead to model overfitting. Another consideration is that small mammal populations often vary immensely year to year due to fluctuating availability of food sources [56]. Replicating this study over a larger sample size for a longer time period would provide greater confidence in our results. A key limitation of this study was that it was only conducted in hardwood forest, and it is unclear how this study would transfer to high canopy cover forests such as boreal forests, temperate forests, or temperate rainforests.

\section{Conclusions}

This study demonstrates that LiDAR has the potential to be used to predict small mammal diversity. This is the first study to our knowledge that relates LiDAR to terrestrial mammal diversity. The best models relating LiDAR predictors with small mammal diversity fit the data well on both a plot and subplot scale (Residual Deviance $=25.20, \mathrm{R}^{2}=0.53$, RMSE $=0.67$, Normalized RMSE $=$ 0.108 and Residual Deviance $=89.20, R^{2}=0.43$, RMSE $=0.51$, Normalized RMSE $=0.089$, respectively) . Though there was a small degree in variation in AICc scores between the top five models in both analyses, multi-model inference revealed that structural diversity was a clear predictor on both scales (Table 4). Structural diversity had a positive relationship with small mammal diversity on both a plot and subplot scale (model averaged plot parameter estimate $=0.53$, variance $=0.32$; subplot parameter estimate $=0.57$, variance $=0.119$ ). However, given the lack of change in AICc between top models, it is likely that most or all of the predictors were relevant in determining small mammal diversity.

The ability of LiDAR to predict not only diversity of 3D-dependent species but also grounddwelling species is a novel finding and could lead the way for an of use of LiDAR for wildlife management. Additionally, if an accurate model based on LiDAR variables can be created for small mammal diversity in various habitats, then LiDAR can have enormous predictive power for small mammal communities and their management. Future research should use LiDAR sensors with higher penetration or ground-truthed models to increase accuracy in understory as well as examine the predictive ability of LiDAR on small mammal diversity over longer time scales and in varied systems. Given that small mammals are crucial components of ecosystems at multiple trophic levels $[14,15,17]$, LiDAR generated variables may have a significant predictive ability for those aspects of ecosystem health.

Supplementary Materials: The following are available online at http://www.mdpi.com/2072-4292/11/19/2222/s1, Table S1: Location coordinates and NLCD vegetation type for NEON small mammal trapping grids, Table S2: Pearson's correlations between LiDAR variables, Table S3: LiDAR calculated values and small mammal diversity for each plot, Table S4: Table of LiDAR-derived variables and small mammal diversity summarized by site, Table S5: Top five models predicting richness as ranked by AICc for plot and subplot-level analysis, Table S6: Table of parameter contributions to richness models, Figure S1: Flow chart of analysis methods, Equation S1: Equation for best model predicting plot-level small mammal diversity, Equation S2: Equation for best model predicting subplot-level small mammal diversity.

Author Contributions: Conceptualization, S.S. and H.S.J.Z.; methodology, S.S. and H.S.J.Z.; software, S.S. and H.S.J.Z.; validation, H.S.J.Z.; formal analysis, S.S. and H.S.J.Z.; investigation, S.S.; resources, S.S. and H.S.J.Z.; data curation, S.S.; writing — original draft preparation, S.S.; writing—review and editing, H.S.J.Z.; visualization, S.S.; supervision, H.S.J.Z.; project administration, S.S. and H.S.J.Z.; funding acquisition, H.S.J.Z.

Funding: This research received no external funding, The APC was funded by Humboldt State University.

Acknowledgments: Thanks to Tim Bean for his encouragement of this project. This material is based in part upon work supported by the National Science Foundation through the NEON Program. The National Ecological Observatory Network is a program sponsored by the National Science Foundation and operated under cooperative agreement by Battelle Memorial Institute. Thanks also to Peter Weishample and Ashley Spink for their information about domain 5 small mammal plots, Trinity Smith for additional help, and our 6 anonymous reviewers whose contributions invaluably improved the quality of this manuscript. The APC was funded by Humboldt State University.

Conflicts of Interest: The authors declare no conflict of interest. 


\section{References}

1. MacAthur, R.H.; MacAthur, J. On bird species diversity. Ecology 1961, 42, 594-598. [CrossRef]

2. Tews, J.; Brose, U.; Grimm, V.; Tielbörger, K.; Wichmann, M.C.; Schwager, M.; Jeltsch, F. Animal species diversity driven by habitat heterogeneity/diversity: The importance of keystone structures. J. Biogeogr. 2004, 31, 79-92. [CrossRef]

3. Coops, N.C.; Tompaski, P.; Nijland, W.; Rickbeil, G.J.M.; Nielsen, S.E.; Bater, C.W.; Stadt, J.J. A forest structure habitat index based on airborne laser scanning data. Ecol. Indic. 2016, 67, 346-357. [CrossRef]

4. Vogeler, J.C.; Cohen, W.B. A review of the role of active remote sensing and data fusion for characterizing forest in wildlife habitat models. Span. Assoc. Remote Sens. 2016, 1-14. [CrossRef]

5. $\quad$ Lindberg, E.; Roberge, J.-M.; Johansson, T.; Hjältén, J. Can airborne laser scanning (ALS) and forest estimates derived from satellite images be used to predict abundance and species richness of birds and beetles in boreal forest? Remote Sens. 2015, 7, 4233-4252. [CrossRef]

6. Sullivan, T.P.; Sullivan, D.S.; Lindgren, P.M.F. Small mammals and stand structure in young pine, seed-tree, and old-growth forest, southwest Canada. Ecol. Appl. 2000, 10, 1367-1383. [CrossRef]

7. Thibault, K.M.; Tsau, K.; Springer, Y.; Knapp, L. TOS Protocol and Procedure: Small Mammal Sampling; revision J; NEON.DOC.000481; National Ecological Observatory Network: Boulder, CO, USA, 2017.

8. Ecke, F.; Löfgren, O.; Sörlin, D. Population dynamics of small mammals in relation to forest age and structural habitat factors in northern Sweden. J. Appl. Ecol. 2002, 39, 781-792. [CrossRef]

9. Fuller, A.K.; Harrison, D.J.; Lachowski, H.J. Stand scale effects of partial harvesting and clearcutting on small mammals and forest structure. For. Ecol. Manag. 2004, 191, 373-386. [CrossRef]

10. Stephens, R.B.; Anderson, E.M. Habitat associations and assemblages of small mammals in natural plant communities of Wisconsin. J. Mammal. 2014, 95, 404-420. [CrossRef]

11. Jaime-González, C.; Acebes, P.; Mateos, A.; Mezquida, E.T. Bridging gaps: On the performance of airborne LiDAR to model wood mouse-habitat structure relationships in pine forests. PLoS ONE 2017, 12, e0182451. [CrossRef]

12. Campos, V.E.; Gatica, G.; Bellis, L.M. Remote sensing variables as predictors of habitat suitability of the viscacha rat (Octomys mimax), a rock-dwelling mammal living in a desert environment. Mammal Res. 2015, 60, 117-126. [CrossRef]

13. Hatten, J.R. Mapping and monitoring Mount Graham red squirrel habitat with Lidar and Landsat imagery. Ecol. Model. 2014, 289, 106-123. [CrossRef]

14. Wang, B.C.; Smith, T.B. Closing the seed dispersal loop. Trends Ecol. Evol. 2002, 17, 379-385. [CrossRef]

15. Moorhead, L.C.; Souza, L.; Habeck, C.W.; Lindroth, R.L.; Classen, A.T. Small mammal activity alters plant community composition and microbial activity in an old-field ecosystem. Ecosphere 2017, 8, e01777. [CrossRef]

16. Brown, J.H.; Heske, E.J. Control of a desert-grassland transition by a keystone rodent guild. Science 1990, 250, 1705-1707. [CrossRef] [PubMed]

17. Gorini, L.; Linnell, J.D.C.; May, R.; Panzacchi, M.; Boitani, L.; Odden, M.; Nilsen, E.B. Habitat heterogeneity and mammalian predator-prey interactions. Mammal Rev. 2012, 42, 55-77. [CrossRef]

18. Hooper, D.U.; Chapin, F.S.; Ewel, J.J.; Hector, A.; Inchausti, P.; Lavorel, S.; Lawton, J.H.; Lodge, D.M.; Loreau, M.; Naeem, S.; et al. Effects of biodiversity on ecosystem functioning: A consensus of current knowledge. Ecol. Monogr. 2005, 75, 3-35. [CrossRef]

19. Tschumi, M.; Ekroos, J.; Hjort, C.; Smith, H.G.; Birkhofer, K. Predation-mediated ecosystem services and disservices in agricultural landscapes. Ecol. Appl. 2018, 28, 2109-2118. [CrossRef]

20. Simonson, W.D.; Allen, H.D.; Coomes, D.A. Applications of airborne lidar for the assessment of animal species diversity. Methods Ecol. Evol. 2014, 5, 719-729. [CrossRef]

21. Burns, K.J. Treehaven Experimental Forest Land Management Plan; UW-Stevens Point College of Natural Resources: Stevens Point, WI, USA, 2009.

22. National Ecological Observatory Network Field Sites Information. Available online: https://www.neonscience. org/field-sites/ (accessed on 20 April 2019).

23. National Forest Service. Management Area Direction; National Forest Service: Rhinelander, WI, USA, 2004.

24. National Ecological Observatory Network. Data Product: TOS Sampling Site Locations. Available online: https://www.neonscience.org/data/spatial-data-maps/ (accessed on 4 March 2018). 
25. National Ecological Observatory Network. Data Products: DP3.30003, DP1.10072. 2018. Available online: http://data.neonscience.org (accessed on 4 March 2018).

26. Krause, K.; Goulden, T. NEON L0-to-L1 Discrete Return LiDAR Algorithm Theoretical Basis Document; revision A; NEON.DOC.001292; National Ecological Observatory Network: Boulder, CO, USA, 2015.

27. Goulden, T.; Hass, B. NEON AOP LMS QA/QC Report for Domain 05; National Ecological Observatory Network: Boulder, CO, USA, 2016.

28. Goulden, T.; Hass, B. NEON AOP QA Report for Domain 5; National Ecological Observatory Network: Boulder, CO, USA, 2016.

29. Goulden, T. NEON Elevation (DTM and DSM) Algorithm Theoretical Basis Document; National Ecological Observatory Network: Boulder, CO, USA, 2019.

30. Azuaje, E.; Jones, K.; Barnett, D.; Meier, C.; Krouss, R.; McKay, J. TOS Protocol and Procedure: Plot Establishment Revision D; National Ecological Observatory Network: Boulder, CO, USA, 2015.

31. Haskell, J.P.; Ritchie, M.E.; Olff, H. Fractal geometry predicts verying body size scaling relationships for mammal and bird home ranges. Nature 2002, 418, 527-530. [CrossRef]

32. Kellner, K.F.; Urban, N.A.; Swihart, R.K. Short-term responses of small mammals to timber harvest in the United States Central Hardwood Forest Region. J. Wildl. Manag. 2013, 77, 1650-1663. [CrossRef]

33. Roussel, J.-R.; Auty, D. lidR: Airborne LiDAR Data Manipulation and Visualization for Forestry Applications. R Package Version 1.4.1. 2018. Available online: https://CRAN.R-project.org/package=lidR (accessed on 20 April 2019).

34. R Core Team. R: A Language and Environment for Statistical Computing; R Foundation for Statistical Computing: Vienna, Austria, 2018.

35. Hijmans, R.J. raster: Geographic Data Analysis and Modeling. R Package Version 3.0.2. Available online: https://CRAN.R-project.org/package=raster (accessed on 20 April 2019).

36. Hill, R.A.; Hinsley, S.A. Airborne lidar for woodland habitat quality monitoring: Exploring the significance of lidar data characteristics when modelling organism-habitat relationships. Remote Sens. 2015, 7, 3446-3466. [CrossRef]

37. Falkowski, M.J.; Smith, A.M.S.; Hudak, A.T.; Gessler, P.E.; Vierling, L.A.; Crookston, N.L. Automated estimation of individual conifer tree height and crown diameter via two-dimensional spatial wavelet analysis of lidar data. Can. J. Remote Sens. 2005, 32, 153-161. [CrossRef]

38. Pretzsch, H. Description and analysis of stand structures. In Forest Dynamics, Growth and Yield; Springer: Berlin/Heidelberg, Germany, 2009; pp. 223-289.

39. Campbell, M.J.; Dennison, P.E.; Hudak, A.T.; Parham, L.M.; Butler, B.W. Quantifying understory vegetation density using small-footprint airborne lidar. Remote Sens. Environ. 2018, 215, 330-342. [CrossRef]

40. van Ewijk, K.Y.; Treitz, P.M.; Scott, N.A. Characterizing forest succession in central Ontario using Lidar-derived Indices. Photogramm. Eng. Remote Sens. 2013, 77, 261-269. [CrossRef]

41. Pallmann, P.; Schaarschmidt, F.; Hothorn, L.; Fischer, C.; Nacke, H.; Priesnitz, K.U.; Schork, N. Testing a user-defined selection of diversity indices. Mol. Ecol. Res. 2012, 12, 1068-1078. [CrossRef] [PubMed]

42. Jost, L. Entropy and diversity. Oikos 2006, 113, 363-375. [CrossRef]

43. Jost, L. Partitioning diversity into independent alpha and beta components. Ecology 2007, 88, 2427-2439. [CrossRef]

44. Calcagno, V. glmulti: Model selection and multimodel inference made easy 2013. R Package Version 2018, $1,498$.

45. Anderson, J.R.; Hardy, E.E.; Roach, J.T.; Witmer, R.E. A Land Use and Land Cover Classification System for Use with Remote Sensor Data; US Government Printing Office: Alexandria, VA, USA, 1976.

46. Yang, L.; Jin, S.; Danielson, P.; Homer, C.; Gass, L.; Bender, S.M.; Case, A.; Costello, C.; Dewitz, J.; Fry, J.; et al. A new generation of the United States National Land Cover Database: Requirements, research priorities, design, and implementation strategies. ISPRS J. Photogramm. Remote Sens. 2018, 146, 108-123. [CrossRef]

47. Burnham, K.P.; Anderson, D.D. Model Selection and Multimodel Inference: A Practical Information-Theoretic Approach, 2nd ed.; Springer: New York, NY, USA, 2002; ISBN 0387953647.

48. Buckland, S.T.; Burnham, K.P.; Augustin, N.H. Model selection: An integral part of inference. Biometrics 1997, 53, 603-618. [CrossRef]

49. Clawges, R.; Vierling, K.; Vierling, L.; Rowell, E. The use of airborne lidar to assess avian species diversity, density, and occurrence in a pine/aspen forest. Remote Sens. Environ. 2008, 112, 2064-2073. [CrossRef] 
50. Goetz, S.; Steinberg, D.; Dubayah, R.; Blair, B. Laser remote sensing of canopy habitat heterogeneity as a predictor of bird species richness in an eastern temperate forest, USA. Remote Sens. Environ. 2007, 108, 254-263. [CrossRef]

51. Froidevaux, J.S.P.; Zellweger, F.; Bollmann, K.; Jones, G.; Obrist, M.K. From field surveys to LiDAR: Shining a light on how bats respond to forest structure. Remote Sens. Environ. 2016, 175, 242-250. [CrossRef]

52. Nelson, R.; Keller, C.; Ratnaswamy, M. Locating and estimating the extent of Delmarva fox squirrel habitat using an airborne LiDAR profiler. Remote Sens. Environ. 2005, 96, 292-301. [CrossRef]

53. Carey, A.B.; Wilson, S.M. Induced spatial heterogeneity in forest canopies: Responses of small mammals. J. Wildl. Manag. 2010, 65, 1014-1027. [CrossRef]

54. Carey, A.B.; Kershner, J.; Biswell, B.; Dominguez de Toledo, L. Ecological scale and forest development: Squirrels, dietary fungi, and vascular plants in managed and unmanaged forests. Wildl. Monogr. 1999, 142, 3-71.

55. Bogdziewicz, M.; Zwolak, R. Responses of small mammals to clear-cutting in temperate and boreal forests of Europe: A meta-analysis and review. Eur. J. For. Res. 2014, 133, 1-11. [CrossRef]

56. Nelson, D.L. Demographic Responses of Small Mammals to Distrurbance Induced by Forest Management. Master's Thesis, Purdue University, West Lafayette, IN, USA, 2017.

57. Martinuzzi, S.; Vierling, L.A.; Gould, W.A.; Falkowski, M.J.; Evans, J.S.; Hudak, A.T.; Vierling, K.T. Mapping snags and understory shrubs for a LiDAR-based assessment of wildlife habitat suitability. Remote Sens. Environ. 2009, 113, 2533-2546. [CrossRef]

58. Srinivasan, S.; Popescu, S.C.; Eriksson, M.; Sheridan, R.D.; Ku, N.W. Terrestrial laser scanning as an effective tool to retrieve tree level height, crown width, and stem diameter. Remote Sens. 2015, 7, 1877-1896. [CrossRef]

59. Zellweger, F.; De Frenne, P.; Lenoir, J.; Rocchini, D.; Coomes, D. Advances in Microclimate Ecology Arising from Remote Sensing. Trends Ecol. Evol. 2019, 34, 327-341. [CrossRef]

60. Sumnall, M.; Fox, T.R.; Wynne, R.H.; Thomas, V.A. Mapping the height and spatial cover of features beneath the forest canopy at small-scales using airborne scanning discrete return Lidar. ISPRS J. Photogramm. Remote Sens. 2017, 133, 186-200. [CrossRef]

61. Mitchell, B.; Walterman, M.; Mellin, T.; Wilcox, C.; Lynch, A.M.; Anhold, J.; Falk, D.A.; Koprowski, J.; Laes, D.; Evans, D.; et al. Mapping Vegetation Structure in the Pinaleño Mountains Using Lidar-Phase 3: Forest Inventory Modeling; Department of Agriculture, Forest Service, Remote Sensing Applications Center: Salt Lake City, UT, USA, 2012.

62. Ecke, F.; Lofgren, O.; Hornfeldt, B.; Eklund, U.; Ericsson, P.; Sorlin, D. Abundance and Diversity of Small Mammals in Relation to Structural Habitat Factors. Ecol. Bull. 2001, 49, 165-171.

63. Fischer, J.; Lindenmayer, D.B. Landscape modification and habitat fragmentation: A synthesis. Glob. Ecol. Biogeogr. 2007, 16, 265-280. [CrossRef] 